\title{
Pengaruh Faktor Sosial Ekonomi Petani Menggunakan Pupuk Organik pada Usahatani Sawi (Studi Kasus di Kecamatan Taebenu, Kabupaten Kupang, NTT)
}

\author{
Ludgardis Trisumarni ${ }^{*}$; Doppy Roy Nendissa, Selfius P.N. Nainiti \\ Program Studi Agribisnis, Fakultas Pertanian, Universitas Nusa Cendana, Kupang NTT \\ *E-mail:serjana0112@gmail.com
}

\begin{abstract}
Many factors influence small farmers to use organic fertilizers in their farming. This study was to analyze the effect of the socio-economic factors of farmers using organic fertilizers on mustard farming. The data used in this study are primary data and secondary data. The method of determining the sample used a census and the determination of the research area was carried out purposively (purposive). Data analysis using binary logistic regression analysis. The results of the study found that the socio-economic factors that influenced farmers using organic fertilizers were age and income, while formal education, non-formal education, farming experience, income level, land area, production costs, and income did not affect.
\end{abstract}

Keywords: Socio-Economic Factors, Mustard Farming, Income, Organic Fertilizer

Abstrak.Banyak faktor yang mempengaruhi para petani kecil menggunakan pupuk organik dalam usataninya. Penelitian ini bertujuan untuk menganalisis pengaruh faktor sosial ekonomi petani menggunakan pupuk organik pada usahatani sawi. Data yang digunakan dalam penelitian ini berupa data primer dan data sekunder. Metode penentuan sampel menggunakan sensus dan penentuan daerah penelitian dilakukan secara sengaja (purposive). Analisis data menggunakan analisis regresi logistik biner. Hasil penelitian menemukan bahwa faktor sosial ekonomi yang mempengaruhi petani menggunakan pupuk organik adalah umur dan pendapatan sedangkan pendidikan formal, pendidikan non formal, pengalaman berusahatani, tingkat pendapatan, luas lahan, biaya produksi, dan penerimaan tidak berpengaruh terhadap penggunaan pupuk organic.

Kata Kunci: Socio-Economic Factors, Mustard Farming, Income, Organic Fertilizer

\section{PENDAHULUAN}

Sistem pertanian yangdominan diterapkan di Indonesia adalah sistem pertanian konvensional. Kenyataan praktiknya sistem pertanian konven-sionalmenggunakan konsep High External Input Agriculture (HEIA) yaitu suatu konsep modern yang menggantungkan produksinya dari senyawa kimiasintetis seperti pupuk, pestisida, bibit unggul dan zat pengatur tumbuh, (Madura,2010). Sistem pertanian konvensional memang dapat mening-katkan produksi pertanian tetapi di sisi lain sistem pertanian secara konvensional juga memberikan dampak buruk bagi lingkungan dan juga kesehatan manusia.

Upaya peningkatan produksi pertanian yang dilakukan oleh petani di Nusa Tenggara Timur juga masih dilakukan secara konvensional dimana petani masih menggunakan pupuk anorganik pada komoditi yang diusahakannya. Hal ini dapat dilihat dari tingkat penggunaan pupuk pada tahun 2018 dimana penggunaan pupuk urea di Nusa Tenggara Timur mencapai 23.440 ton, pupuk ZA sebanyak 1640 ton, pupuk SP sebanyak 4.820 ton dan pupuk NPK sebanyak 15.490 ton sedangkan pupuk organik hanya sebesar 3.110 ton(sumber: http://distan.nttprov.go.id/index.php/kinerja/).

Petani umumnya masih bergantung pada pupuk anorganik dalam upaya meningkatkan produktivitas usahataninya. Hal ini dapat dilihat dari besarnya selisih antara penggunaan pupuk 
anorganik dan pupuk organik pada tahun 2018 di Kabupaten Kupang, yaitu sebanyak 679,32 ton pupuk anorganik dan pupuk organik hanya 66,05 ton (sumber: http://distan.nttprov.go.id/index.php/basis_cat/penyuluhan-prasarana-sarana pertanian/)

Tren keamanan pangan dan tingginya permintaan pasar terhadap bahan pangan organik seharusnya mendorong petani untuk menggunakan pupuk organik pada usahataninya. Namun kenyataannya tidak banyak petani yang menggunakan pupuk organika dalam usahatanianya. Berbagai faktor dapat menjadi pemicu atau penghambat dalam melakukannya. Karakteristik sosial ekonomi petani setempat dapat membawa pengaruh kuat atau lemah dalam penggunaak pupuk organik.

Studi tentang pengaruh faktor-faktor sosial ekonomiterhadap ushatani dan penggunaan pupuk atau pertanian organik banyak ditemukan dalam literatur baik di dalam luar negeri dan di Indonesia. Beberapa studi yang dilakukan Maiangwa, (2008) tentang adopsi pupuk organik di dua wilayah berbeda di Nigeria; Paudel, et al (2009 tentang adopsi pupuk kandang untuk tanaman jagung di Nepal; Ajewole, O. C. (2010) tentang penggunaan pupuk organik yang komesial di Oyo State Nigeria; dan Adesope, et al, (2012) tentang adopsi praktek menerapkan pertanian organik diRivers State in Niger Delta, Nigeria. Para peneliti tersebut menggunakan metode deskriptif, uji beda dan analisis regresi menggunakan tobit. Sedangkan beberapa literatus hasil studi yang di lakukan di Indonesia tentang pengaruh faktor-faktor sosial ekonomi terhadap usahatani antara lain oleh Susanti, (2008) tentang faktor-faktor yang mempengaruhi pengambilan keputusan petani dalam penerapan pertanian padi organik di Kabupaten Sragen; Naibaho, et al (2012) tentang pengaruh faktor sosial ekonomi petani terhadap produksi usahatani sawi di Sumatera Utara; Amala, et al, (2014) tentang faktor-faktor yang berhubungan dengan tingkat adopsi petani terhadap sistem pertanian padi organik di Deliserdang; Usboko, et al (2016) tentang faktor sosial ekonomi yang mempengaruhi produksi usahatani sayuran sawi di Timor; Amin dan Adita (2018) tentang pengaruh sosialekonomi petani bawang merah terhadap penerapanzeolit dan pupuk organik di Kabupaten Brebes; Kusnadi dan Jafar, (2019) tentang faktor sosial ekonomi yang mempengaruhi produksi padi organik di Tasikmalaya; Wijaya, (2019) tentang analisis faktor-faktor yang mempengaruhi keputusan petani terhadap penggunaan pupuk organik di Kabupaten Pacitan; danSumarno, et al (2019) tentang adopsi inovasi pengelolaan tanaman terpadu jagung di Gorontalo; Studi tersebut memberikan hasil yang sedikit berbeda-beda, kemungkinan karena perbedaan karakteristiksosial ekonomi setiap wilayah karena pengaruh perdedaan sosio ekonomidemografi dan kutural.

Penelitian ini menyoroti kondisi karakteristik usahatani sawi dan faktor-faktor sosial ekonomi apa saja yang mempengaruhi petani menggunakan pupuk organik pada usahatani sawi. Mengingat mayoritas masyarakat adalah bertani hortikutura namun dalam mengamatan tidak banyak petani yang menggunakan pupuk organik. Penelitian ini dapat menemukan faktor sosial ekonomi dominan yang dapat di memicu petani menggunakan pupuk organik.

\section{METODE}

\subsection{Lokasi dan Waktu Penelitian}

Penelitian ini merupakan studi kasus pada dua kelompok tani. Kecamatan Taebenu Kabu-paten Kupang yaitu Kelompok Tani.Menggunakan 50 petani merupakan populasi petani yang menggunakan pupuk organik dalam usahatani sawi. Mengukur pendapatan analisis masukan-keluaran atau Inputoutput (I-O)(Soekartawi, 2006). Penyusutan terhadap penggu-nakan faktor proksi menggunakan metode garis Straight Line Method, (Badriwan, 2004; 308):Mengukur kelayakanusahatani sawi R/C rasio (R/C > 1 di anggap layak).

\subsection{Jenis dan Sumber Data}

Jenis dan sumber data yang digunakan dalam penelitian ini adalah data primer dan sekunder. Data primer diperoleh dengan cara melakukan wawancara kepada petani sampel dengan menggunakan daftar pertanyaan yang telah disiapkan sebelumnya. Sedangkan data sekunder diperoleh dari dinas ataupun kementerian terkait sebagai sumber untuk menentukan lokasi penelitian, serta literaturliteratur yang juga berhubungan dengan penelitian ini.

\subsection{Metode Penentuan Responden}

Penentuan sampel desa penelitian dilakukan secara purposive, yaitu diambil 3 desa di Kecamatan Barambai yang menjadi sentra produksi padi sawah. Sampel desa yang terpilih adalah Desa Bagagap, Desa Barambai Kolam Kiri Dalam dan Desa Karya Tani., Selanjutnya petani responden di tiap desa 
diambil dengan metode proportioned random sampling, yaitu menggunakan rumus $n_{i}=\frac{n k}{N} x \quad n$, sehingga diperoleh 15 petani sampel di Desa Bagagap, 16 petani sampel di Desa Barambai Kolam Kiri Dalam, dan 29 petani sampel di Desa Karya Tani, maka didapat 60 responden petani sampel

\subsection{Analisis Data}

Analisis faktor-faktor sosial ekonomi yang mempengaruhi petani menggunakan pupuk organikpendekatan regresi logistik biner. Penerapan regresi model logistik biner menganalisis perilaku rumah tangga petani terkait faktor-faktor yang mempengaruhi petani menggunakan pupuk organik pada usahatani sawi Model dari faktor-faktor yang mempengaruhi petani menggunakan pupuk organik yang akan diduga dengan fungsi logit adalah;

$$
\begin{array}{r}
g(X)=\alpha+\beta_{1} X_{1}+\beta_{2} X_{1}+\beta_{3} X_{3}+\beta_{4} X_{1} \\
+\beta_{6} X_{6} \beta_{7} X_{7} \beta_{8} X_{8} \ldots \ldots .1
\end{array}
$$

Di mana;

$\alpha \quad=$ konstanta

$\mathrm{X}_{\mathrm{um}}=$ Umur

$\mathrm{X}_{\mathrm{pf}}=$ Pendidikan formal

$\mathrm{X}_{\mathrm{pnf}}=$ Pendidikan non formal

$\mathrm{X}_{\mathrm{pgu}}=$ Pengalaman berusahatani

$\mathrm{X}_{\mathrm{lsl}}=$ luas lahan

$\mathrm{X}_{\mathrm{bp}}=$ biaya produksi

$\mathrm{X}_{\mathrm{pnr}}=$ penerimaan

$\mathrm{X}_{\mathrm{Pd}}=$ pendapatan

Pengujian melalui tahapan:

-Uji simultan; Uji serentak dilakukan untuk mengetahui signifikansi paramet $\beta$ terhadap variabel respon secara keseluruhan. Pengujian signifikansi parameter tersebut menggunakan statistik uji G, dimana statistik uji G mengikuti distribusi Chi-Square.

-Uji wald; Uji Wald digunakan untuk menguji pengaruh variabel bebas secara parsial terhadap variabel terikat. Dengan taraf signifikansi sebesar 5\%, tolak H0 apabila nilai statistic wald $>\alpha$ artinya faktor tersebut mempunyai pengaruh yang nyata terhadap pengambilan keputusan petani responden menggunakan pupuk organik atau tidak.

-Uji Tingkat Signifikansi;Pengujian tingkat signifikansi digunakan untuk menguji koefisien regresi dengan melihat nilai signifikansi yang dihasilkan dari uji regresi logit. Pengujian hipotesis dilakukan dengan cara membandingkan tingkat signifikan dengan nilai $\alpha$ $(0,05)$.Goodness of fit testdigunakan untuk menguji apakah model yang dihasilkan fit atau tidak.; Uji serentak dilakukan untuk mengetahui signifikansi paramet $\beta$ terhadap variabel respon secara keseluruhan. Pengujian signifikansi parameter tersebut menggunakan statistik uji G, dimana statistik uji G mengikuti distribusi Chi-Square.

-Uji wald; Uji Wald digunakan untuk menguji pengaruh variabel bebas secara parsial terhadap variabel terikat. Dengan taraf signifikansi sebesar 5\%, tolak H0 apabila nilai statistic wald $>\alpha$ artinya faktor tersebut mempunyai pengaruh yang nyata terhadap pengambilan keputusan petani responden menggunakan pupuk organik atau tidak.

-Uji Tingkat Signifikansi; Pengujian tingkat signifikansi digunakan untuk menguji koefisien regresi dengan melihat nilai signifikansi yang dihasilkan dari uji regresi logit. Pengujian hipotesis dilakukan dengan cara membandingkan tingkat signifikan dengan nilai $\alpha(0,05)$. Goodness of fit testdigunakan untuk menguji apakah model yang dihasilkan fit atau tidak.

\section{HASIL DAN PEMBAHASAN}

\subsection{Analisis Pendapatan}

Analisis pendapatan dilakukan untuk menentukan nilai yang diperoleh petani dari kegiatan berusahatani sawi. Pendapatan diperoleh dari selisih antara penerimaan dan total biaya produksi. Dalam penelitian ini, analisis pendapatan usahatani sawi hanya untuk satu periode tanam yaitu JuliAgustus 
Tabel 1. Pendapatan usahatani sawi di Desa Baumata Timur selama satu periode musim tanam per 0,1378 ha, 2019

\begin{tabular}{|c|c|c|c|}
\hline Uraian & Fisik & $\operatorname{Harga}(\mathrm{Rp})$ & Jumlah(Rp) \\
\hline $\begin{array}{l}\text { Biaya variabel } \\
\text {-Benih } \\
\text {-Pupuk } \\
\text {-Pestisida } \\
\text {-Tenaga kerja } \\
\text { luar keluarga } \\
\text {-tansportasi }\end{array}$ & $\begin{array}{c}114,00 \mathrm{gr} \\
37,4(\mathrm{~kg}) \\
2,14 \\
\quad-\end{array}$ & $\begin{array}{c}764,00 \\
500,00 \\
47.900 \\
-\end{array}$ & $\begin{array}{r}87.096 \\
68.700 \\
102.506 \\
- \\
35.871 \\
\end{array}$ \\
\hline $\begin{array}{l}\text { Biaya tetap } \\
\text {-Penyusutan }\end{array}$ & & & 12.960 \\
\hline $\begin{array}{l}\text { Penerimaan } \\
\text {-total produksi } \\
\text {-Harga } \\
\text { Total } \\
\text { penerimaan }\end{array}$ & 906 ikat & 2000 & 1.812 .000 \\
\hline TVC & & & 294.173 \\
\hline TFC & & & 12.960 \\
\hline $\mathrm{TC}(4+5)$ & & & 307.133 \\
\hline Penerimaan & & & 1.812 .000 \\
\hline Pendapatan(7-6) & & & 1.504 .867 \\
\hline $\mathrm{R} / \mathrm{C}=7 / 6$ & & & 5,899 \\
\hline
\end{tabular}

Sumber: Analisis data primer

Berdasarkan tabel di atas, untuk melakukan usahatani per 0,1378 ha, petani mengeluarkan biaya sebesar Rp307.133 per satu musim tanam. Dengan pengeluaran sebanyak itu, petani memperoleh 906 ikat sawi karena petani biasanya menjual sawi dengan menggunakan satuan ikat dengan harga 2000/ikat maka penerimaan yang diperoleh petani adalah sebesar Rp 1.812.000. Jadi, pendapatan yang diperoleh petani adalah sebesar Rp1.504.867 artinya usahatani sawi tersebut menguntungkan. Hal ini dapat dilihat nilai $\mathrm{R} / \mathrm{C}$ ratio yaitu 5,899 yang menunjukkan bahwa penggunaan penggunaan Rp100.000.000 akan menghasilkan Rp589.900.000 artinya usahatani sawi yang menggunakan pupuk organik tersebut menguntungkan karena penerimaan yang lebih besar daripada pengeluaran.

\subsection{Uji Simultan}

Untuk uji simultan setelah data dianalisis dengan menggunakan STATA, dapat disimpulkan bahwa, dengan nilai LR chi2 sebesar 44,76 dengan tingkat signifikansi sebesar $10 \%$ terdapat cukup bukti untuk menyatakan bahwa terdapat minimal satu variabel yang secara signifikan berpengaruh terhadap variabel dependen. Dengan nilai Pseudo R2 sebesar 0,6740 artinya keragaman data variabel independen mampu menjelaskan keragaman data variabel dependen sebesar 67,4\%.

\subsection{Uji Wald}

Table 2. output regresi logistic dan odds ratio

\begin{tabular}{|l|cccccc|}
\hline $\mathrm{y} \mid$ Coef. & Std. Err. $\mathrm{z}$ & $\mathrm{P}>|\mathrm{z}|$ & \multicolumn{3}{l}{ [95\% Conf. Interval] } \\
\hline $\mathrm{X}_{\mathrm{um}} \mid$ & 3.850 & 1.6220 & 2.37 & 0.018 & .6716 & 7.0298 \\
$\mathrm{X}_{\mathrm{pf}} \mid$ & -.1150 & .7144 & -0.16 & 0.872 & -1.5152 & 1.2851 \\
$\mathrm{X}_{\text {prf }} \mid$ & .7530 & 1.4822 & 0.51 & 0.611 & -2.1521 & 3.6582 \\
$\mathrm{X}_{\text {pgu }} \mid$ & 2.059 & 1.3863 & 1.49 & 0.137 & -.65726 & 4.7770 \\
$\mathrm{X}_{\mathrm{lsl}} \mid$ & -2.280 & 1.4795 & -1.54 & 0.123 & -5.1805 & .6191 \\
$\mathrm{X}_{\mathrm{bp}} \mid$ & 1.229 & 1.2289 & 1.00 & 0.317 & -1.1792 & 3.6380 \\
$\mathrm{X}_{\text {pn }} \mid$ & 1.554 & 1.4729 & 1.06 & 0.291 & -1.3324 & 4.4413 \\
$\mathrm{X}_{\mathrm{pd}} \mid$ & 5.248 & 1.8960 & 2.77 & 0.006 & 1.5326 & 8.9648 \\
$\mathrm{Cons}$ & -9.499 & 3.7247 & -2.55 & 0.011 & -16.7990 & -2.1985 \\
\hline
\end{tabular}

Sumber: Analisis data primer

Berdasarkan tabel di atas, secara parsial hasil uji Wald yang ditunjukkan koefisien Z, menunjukan bagaimana pengaruh variabel-variabel independen secara parsial 


\subsection{Uji Tingkat Signifikansi}

Berdasarkan table 1, dapat kita lihat bahwa variabel-variabel independen yang tidak mempengaruhi variabel dependen secara signifikan adalah pendidikan formal, pendidikan non formal, pengalaman berusahatani, luas lahan, biaya produksi dan penerimaan karena nilai signifikansi dari tiap variabelvariabel independen tersebut lebih besar dari nilai $\alpha$ yaitu 0,05. Sedangkan umur dan pendapatan mempengaruhi petani di Desa Baumata Timur menggunakan pupuk organik secara signifikan karena signifikansinya lebih kecil dari 0,05 . Setelah dilakukan uji signifikansi parameter di atas, maka model regresi logistik dapat dibentuk dengan menggunakan nilai taksiran parameter pada table 1 . Model yang terbentuk adalah;

$\mathrm{g}(\mathrm{x})=-1,232+0,997 \mathrm{Xum}+0,062 \mathrm{Xpf}+0,595 \mathrm{Xpnf}-0,011 \mathrm{Xpgu}-0,357 \mathrm{Xlsl}-1,020 \mathrm{Xbp}+0,899 \mathrm{Xpn}+0,314 \mathrm{X}$ GOODNESS OF FIT PEARSON TEST

Berdasarkan hasil analisis menggunakan STATA, nilai goodness of fit pearson sebesar 44,06>0,05, artinya Ho diterima. Jadi dengan tingkat signifikansi 5\% terdapat cukup bukti bahwa model yang digunakan adalah fit.

\subsection{Faktor-faktor yang Mempengaruhi Petani Menggunakan Pupuk Organik Pada Usahatani Sawi}

Temuan penelitian menunjukan bahwa terdapat pengaruh umur dan pendapatan petani terhadap petani dalam menggunakan pupuk organic, hal ini ditunjukkan dengan dengan nilai $\mathrm{p}$ value $<0.05$. odd ratio untuk variable umur 0.6716 menunjukkan bahwa petani yang umur lebih tua cenderung menggunkan pupuk oraganik 0.6716 kali dibandingkan dengan petani yang umur lebih mudah. Sementara efek pendapatan ditandai dengan nilai odds ratio sebesar 1.5326 artinya petani dengan pendapatan tinggi cenderung menggunakan pupuk organic 1.5326 dibandikan petani yang tidak menggunakan pupuk oraganik.

Berdasarkan hasil uji table secara parsial, pendidikan formal tidak berpengaruh secara signifikan terhadap petani dalam penggunaan pupuk organik pada usahatani sawi dengan koefisien $\mathrm{Z}$ sebesar 0,16 dan nilai signifikansi sebesar -1,515. Dengan nilai odds ratio sebesar 0,891 yang artinya kecendrungan petani dengan latar belakang lulusan SD dan SMP menggunakan pupuk organik pada usahatani sawi 0,891 kali lebih kecil dibandingkan dengan petani yang latar belakang pendidikannya SMA dan Sarjana sebatas. Semakin rendah pendidikan seseorang maka pemikirannya semakin sempit dan wawasannya juga sempit sehingga sangat sulit untuk menerima inovasi-inovasi baru, begitupu sebaliknya.

Selain pendidikan formal, pendidikan non formal tidak berpengaruh secara signifikan terhadap petani dalam penggunaan pupuk organik pada usahatani sawi dengan koefisien $\mathrm{Z}$ sebesar 0,51 dan nilai signifikansi sebesar -2,512. Dengan nilai odds ratio sebesar 2,123 yang artinya kecendrunganmenggunakan pupuk organik pada usahatani sawi bagi petani yang mengikuti pendidikan formal dengan frekuensi 4-5 kali dalam setahun, 2,123 kali lebih tinggi dibandingkan dengan petani yang mengikuti pendidikan formal 1-3 dalam setahun.

Menurut Soekartawi (1999) dalam Siregar (2015), pengalaman seseorang dalam berusaha berpengaruh dalam menerima inovasi dari luar. Bagi yang mempunyai pengalaman yang sudah cukup lama akan lebih mudah menerapkan inovasi dari pada pemula. Teori ini didukung juga oleh Lubis (2000) dalam Siregar (2015) yang berpendapat bahwa orang yang mempunyai pengalaman relatif berhasil dalam mengusahakan usahanya, biasanya mempunyai pengetahuan, sikap dan keterampilan yang lebih baik dibandingkan dengan orang yang kurang berpengalaman.

Berdasarkan hasil uji table secara parsial, pengalaman berusahatani tidak berpengaruh secara signifikan terhadap petani dalam penggunaan pupuk organik pada usahatani sawi. efek adopsi dengan pengalaman berusahatani adalah positif karena koefisien $\mathrm{Z}$ bertanda positif yaitu 1,49 dengan nilai signifikansi sebesar $-0,657$. nilai positif ini berarti semakin banyak pengalaman petani maka semakin besar peluang petani menggunakan pupuk organik. Dariodds ratio sebesar 7,844 yang artinya peluang petani yang pengalaman berusahataninya berkisar dari 6-12 tahun 7,844 lebih tinggi menggunakan pupuk organik dibandingkan dengan petani yang pengalaman berusahataninya 2-5 tahun.

Luas lahan dengan keputusan untuk menggu-nakan pupuk organik tidak memiliki hubungan. Hal ini ditujukkan dengan hasil uji table secara parsial, dimana koefisien Z bernilai -1,54. Nilai signifikansi sebesar $-5,180$ lebih besar dari nilai $\alpha$. Nilai odds ratio sebesar 0,102 yang artinya peluang petani dengan luas lahan 5-12 are menggunakan pupuk organik pada usahatani sawi lebih besar hampir satu kali dibandingkan dengan petani yang memiliki luas lahan 13-25 are. Hal ini 
menggambarkan bahwa semakin kecil lahan yang dimiliki petani semakin kecil pula peluang petani untuk mengadopsi sebuah inovasi dalam hal ini penggunaan pupuk organik.

Berdasarkan hasil uji table secara parsial, biaya produksi tidak berpengaruh secara signifikan terhadap petani dalam penggunaan pupuk organik pada usahatani sawi dengan nilai signifikansi sebesar $-1,179$ dan koefisien $Z$ sebesar 1,00. Nilai odds ratio sebesar 3,419 yang artinya peluang petani dengan total biaya produksi Rp300.000-Rp699.000 menggunakan pupuk organik pada usahatani sawi 3,419 lebih tinggi dibandingkan dengan petani yang mengeluarkan biaya produksi sebesar Rp100.000-Rp299.999.

Faktor penerimaan berpengaruh secara signifikan terhadap petani dalam penggunaan pupuk organik pada usahatani sawi dengan nilai signifikansi sebesar -1,332 dan koefisien Z sebesar 1,06. Dengan nilai odds ratio sebesar 4,732 yang artinya peluang petani yang penerimaannya Rp1.500.000Rp3.599.999 menggunakan pupuk organik pada usahatani sawi, 4,732 kali lebih tinggi dibandingkan dengan petani yang penerimaannya berkisar dari Rp500.000-Rp1.499.999. Hal ini berarti semakin tinggi penerimaan yang diperoleh oleh petani semakin tinggi pula peluang petani menggunakan pupk organik.

\section{KESIMPULAN}

Umur dan pendapatan mempengaruhi petani menggunakan pupuk organik pada usahatani sawi sedangkan faktor sosial ekonomi lainnya tidak berpengaruh. Orientasi perilaku hidup petani di daerah ini mengatakan bahwa pendapatan yang tinggi bukan menjadi target usaha setiap petani.

\section{DAFTAR PUSTAKA}

Abidin Zainal; Bananiek Sri. 2013. FaktorFaktor Sosial Ekonomi yang MempengaruhiAdopsi Teknologi Pengelolaan Tanaman Terpadu Padi Sawah di Sulawesi Tenggara. Jurnal Pengkajian danPengembangan Teknologi Pertanian.

Adesope, O. M., Matthews-Njoku, E. C., Oguzor, N. S., dan Ugwuja, V. C. 2012. Effect of SocioEconomic Characteristics of Farmers on Their Adoption of Organic Farming Practices. Crop Production Technologies, 210-220.

Ajewole, O. C. 2010. Farmers response to adoption of commercially available organic fertilizers in Oyo state, Nigeria. African Journal of Agricultural Research, 5(18), 2497-2503.

Amala, T. A., Chalil, D., dan Sihombing, L. 2014. Faktor-faktor yang Berhubungan dengan Tingkat Adopsi Petani terhadap Sistem Pertanian Padi Organik (Studi Kasus: Desa Lubuk Bayas, Kecamatan Perbaungan, Kabupaten Serdang Bedagai). Journal of Agriculture and Agribusiness Socioeconomics, 2(11), 15156.

Amin, M., dan Adita, D. 2018. Pengaruh Sosial-Ekonomi Petani Bawang Merah Terhadap Penerapanzeolit dan Pupuk Organik di Kabupaten Brebes. In prosiding seminar nasional fakultas pertanian (Vol. 1, No. 1).

Badan Pusat Statistik. 2017. Kecamatan Taebenu dalam Angka 2017. https://kupangkab.bps.go.id/publication/2018/09/26/8ec64fd9291d4ba0ba b990ea/ kecamatantaebenu- dalam-angka-2018.html. Diakses pada 16/01/2020

Badan Pusat Statistik. 2018. Kecamatan Taebenu dalam Angka 2018. https://kupangkab.bps.go.id/publication/2018/09/26/8ec64fd9291d4ba0ba b990ea/kecamatan taebenu- dalam-angka-2018.html Diaksespada 16/01/2020.

CharinaAnne; Andriani Rani; Kusum Budi; Hermita Sadel Agriani; Deliana Yosini. 2018. Faktorfaktor yang Mempengaruhi Petani dalam Menerapkan Standar Operasional Prosedur (SOP) Sistem Pertanian Organik. Skripsi.Bandung Barat.Universitas Padjadjaran.

Dinas Pertanian, NTT. 2018 . Peta Alokasi Pupuk Bersubsidi di NTT. http://distan.nttprov.go.id tentang Peta Alokasi Pupuk Bersubsidi Diakses pada 16 Juni 2019).

Dinas Pertanian, NTT. 2018. Penyuluhan, Prasarana-sarana Pertanian. .http://distan.nttprov.go.id/index.php/basis_cat/penyuluhan-prasarana-sarana-sarana pertanian/. Diakses pada 09/09/19.

Ginting, M., \& Sebayang, I. 2014. Analisis Pengaruh Faktor Sosial Ekonomi Petani terhadap Luas Tanam Bawang Merah di Berdasarkan Pendapat Petani di Kabupaten Dairi. Journal of Agriculture and Agribusiness Socioeconomics, 3(1), 15176. 
Halono, Oktani; Sembiring Pasukat. 2013. Penerapan Analisis Regresi Logistik

pada Pemakaian Alat Kontrasepsi Wanita. Jurnal Saintia Matematika vol.1,pp55-61.

Harlan, Johan. 2018. Analisis Regresi Logistic. Jakarta. Gunadarma.

Kusnadi, N., \& Jafar, R. 2019. Faktor Sosial Ekonomi yang Mempengaruhi Produksi Padi Organik di Tasikmalaya. Jurnal Ekonomi Pertanian dan Agribisnis, 3(4), 730-737.

Kab-kupang.go.id/kupang2010/2010/wpcontent/ uploads/2018/04/Laporan- Kinerja-instansiPemerintah-Kabupaten-Kupang-Tahun-2017. Diakses pada 12 Juni 2019.

Kab-kupang.go.id tentang Laporan-Kinerja-InstansiPemerintahKabupatenKupangTahun2017; (diaksespada 10 Juni 2019).

Madura Uftori. 2010. Kesuburan Tanah. DikutipdariUftoriwasit.blogspot.com/2010/10/kesuburantanah.html [23 Mei 2017].

Maiangwa, M. G. 2008. Adopsi Pupuk Kimia Yang Dipengaruhi Oleh Karakteristik Sosial-Ekonomi Petani Di Zona Barat Laut (Nwz) Nigeria. Jurnal Global Ilmu Pertanian, 7 (1), 97-104.

Mardikanto Totok. 1993. PenyuluhanPemba-ngunan Pertanian. Sebelas MaretUniversity Press. Surakarta.

Matata, P. Z., Ajay, O. C., Oduol, P. A., \& Agumya, A. (2010). Socio-economic factors influencing adoption of improved fallow practices among smallholder farmers in western Tanzania. African journal of agricultural research, 5(9), 818-823.

Naibaho, T. T., Fauzia, L., \& Emalisa, E. 2012. Pengaruh Faktor Sosial Ekonomi Petani Terhadap Produksi Usahatani Sawi. Journal of Agriculture and Agribusiness Socioeconomics, 1(1), 15343.

Sihombing Tulus. 1991. Faktor-Faktor Yang Mempengaruhi Penggunaan Teknologi di Pedesaan Tapanuli Utara. Skripsi FakultasPer-tanian Institut Pertanian Bogor.

Sumarno, J., Gorontalo, B. P. T. P., Hiola, F. S. I., dan Gorontalo, B. P. T. P. 2019. Faktor SosialEkonomi Yang Mempengaruhi Petani Mengadopsi Inovasi Pengelolaan Tanaman Terpadu Jagung Di Gorontalo.

Paudel, P., Shrestha, A. K., \& Matsuoka, A. 2009. Socio-economic factors influencing adoption of fertilizer for maize production in Nepal: A cast study of Chitwan district (No. 351-2016-17994).

Susanti Lisana. 2008. Faktor-Faktor Yang Mempengaruhi Pengambilan KeputusanPetani Dalam Penerapan Pertanian Padi Organik.Skripsi. Surakarta.Universitas SebelasMaret.

Usboko, A. M., \& Fallo, Y. M. 2016. Faktor Sosial Ekonomi yang Mempengaruhi Produksi Usahatani Sayuran Sawi di Kelompok Tani Mitra Timor. Agrimor, 1(03), 60-62.

Wijaya, A. K. 2019. Analisis Faktor-Faktor yang Mempengaruhi Keputusan Petani terhadap Penggunaan Pupuk Organik di Kabupaten Pacitan. 